Tema: Metalurgia Secundária

\title{
MODELAMENTO MATEMÁTICO DAS PERDAS TÉRMICAS EM PANELAS DE ACIARIA*
}

\author{
Izabela Diniz Duarte ${ }^{1}$ \\ Carlos Antonio da Silva ${ }^{2}$ \\ Itavahn Alves da Silva ${ }^{3}$ \\ Eliana Rodrigues Ferreira ${ }^{5}$ \\ Alexandre Leopoldo Pereira ${ }^{5}$ \\ Varadarajan Seshadri ${ }^{7}$
}

\section{Resumo \\ O controle da temperatura do aço líquido desde o refino secundário até o lingotamento é condição essencial para alcançar alto nível de qualidade do produto final e economia de energia, o que permite ressaltar a importância de se determinar as perdas térmicas na panela. Entre outros fatores este trabalho buscou identificar a importância relativa das perdas térmicas para o revestimento refratário e através da escória. A temperatura, espessura da camada de escória, temperatura do revestimento refratário, propriedades físicas e características de convecção foram os fatores considerados. Cálculos numéricos que quantificam essas perdas. \\ Palavras-chave: Aciaria; Panela; Perdas térmicas. \\ MATHEMATICAL MODELING OF HEAT LOSSES FROM A STEELMAKING LADLE}

\begin{abstract}
The main factors that determine heat losses in a steelmaking ladle are reviewed. Controlling the temperature of the liquid steel from the primary refining until casting is essential to achieve product quality as well as energy savings. Among other objectives this study sought to assess the relative weight of heat losses to the refractory lining and the thermal losses through the slag layer. Temperature, slag thickness and properties, refractory temperature and physical properties and convection characteristics are the defining factors. Numerical calculations are performed.
\end{abstract}

Keywords: Steelmaking; Ladle; Thermal losses.

1 Engenheira Metalurgista, Mestranda em Engenharia de Materiais, Redemat, Universidade Federal de Ouro Preto (UFOP), Minas Gerais, Brasil.

2 Engenheiro Metalurgista, Ph.D., Professor, Universidade Federal de Ouro Preto (UFOP), Campus Morro do Cruzeiro, Escola de Minas, Ouro Preto, MG, Brasil.

3 Engenheiro Metalurgista, DSc. Professor, Universidade Federal de Ouro Preto (UFOP), Campus Morro do Cruzeiro, Escola de Minas, Ouro Preto, MG, Brasil.

4 Engenheira Mecânica, DSc. Professor, Universidade Federal de Ouro Preto (UFOP), Campus Morro do Cruzeiro, Escola de Minas, Bairro Bauxita, Ouro Preto, MG, Brasil. E-mail:

5 Graduando em Metalurgia, UFOP, Campus Morro do Cruzeiro, Escola de Minas, Ouro Preto, MG, Brasil.

6 Engenheiro Metalurgista, Dr. Ing. Professor Emérito, Universidade Federal de Minas Gerais (UFMG), Belo Horizonte, MG, Brasil.

* Contribuição técnica ao 450 Seminário de Aciaria - Internacional, 25 a 28 de maio de 2014, Porto Alegre, RS, Brasil. 


\section{INTRODUÇÃO}

Sob a ótica metalúrgica, o ajuste e controle do grau de superaquecimento do aço, ao término da operação de refino secundário, é precondição para estabilidade operacional e qualidade interna e superficial do produto final de lingotamento contínuo. Os fatores que influenciam sobre as perdas térmicas da panela incluem a geometria da panela, composição e grau de desgaste do revestimento; estado térmico da panela antes do seu enchimento; grau de superaquecimento do aço líquido; nível de enchimento da panela; espessura e composição da escória de cobertura; utilização de cobertura da panela. Gastón et al. [1] apontam que, durante o lingotamento contínuo, uma condição de alto grau de superaquecimento do aço intensifica a segregação central durante o lingotamento contínuo; enquanto que um baixo grau de superaquecimento incorre em aprisionamento de inclusões no veio, entupimento das saídas do distribuidor para o molde, além de prejudicar a fusão do pó fluxante e aderência no molde. Deve-se ressaltar ainda que condição de alta temperatura do aço líquido normalmente incorre ainda em aumento do nível de desgaste do revestimento refratário da panela, podendo comprometer a produtividade. A Figura 1 mostra os perfis de temperatura durante a drenagem da panela de aço e a evolução da temperatura do aço na panela e no distribuidor.
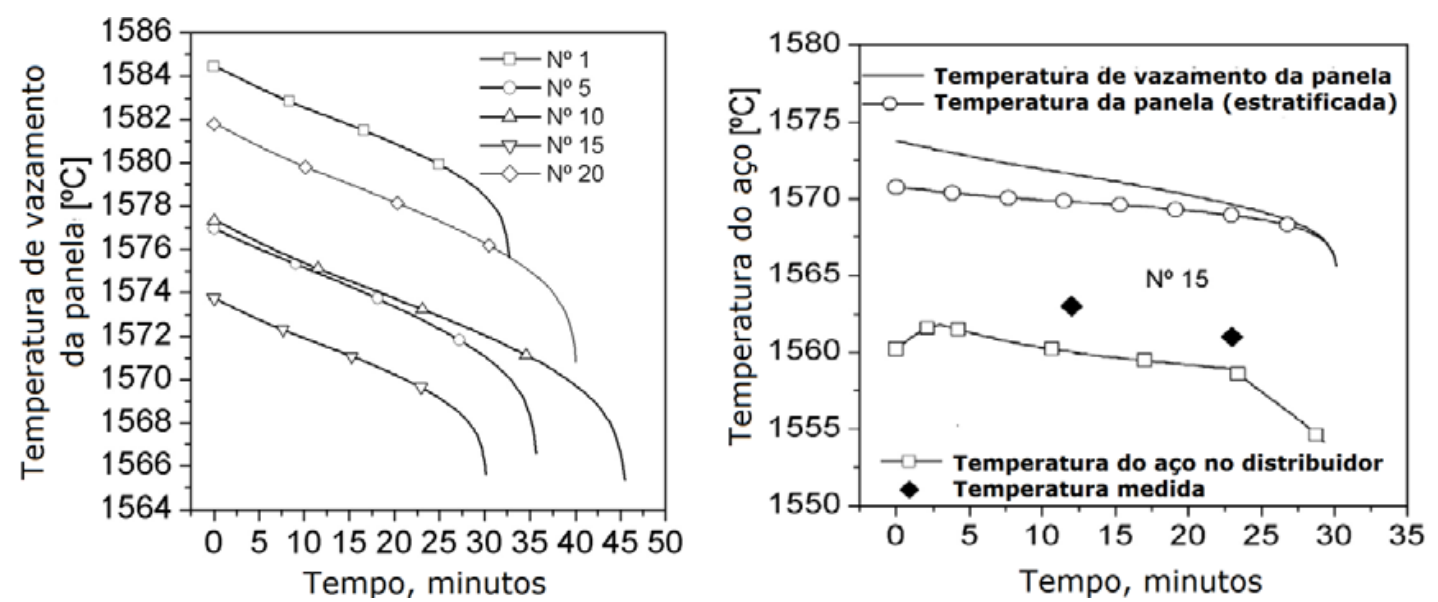

Figura 1. a) Evolução da temperatura de vazamento da panela para diferentes corridas b) evolução das temperaturas de vazamento, na panela e no distribuídor [1].

As principais perdas térmicas do aço contido na panela são devidas a: 1 acumulação ou armazenamento de calor no revestimento refratário; 2 - condução de calor do banho metálico para o revestimento refratário da parede lateral e do fundo; 3 - convecção e radiação de calor da camada de escória para a atmosfera. No caso da panela vazia e sem tampa a perda térmica por radiação é significativa. A temperatura da carcaça e a quantidade de energia armazenada no conjunto carcaça/refratários são dependentes do tipo e do grau de desgaste do revestimento refratário e também do número de corridas efetuadas, além da eficiência da operação de pré-aquecimento da panela. A Figura 2a mostra que a utilização de revestimento de espinélio (comparativamente a revestimento dolomítico) faz com que a temperatura da carcaça atinja níveis de estabilização em períodos mais curtos. Já a Figura $2 b$ mostra que a quantidade de energia acumulada num revestimento de espinélio é maior do que no caso de panela revestida com magnésia. Com isto, as perdas térmicas em uma panela revestida com espinélio são maiores, mesmo para diferentes graus de desgaste. Volkova \& Janke [2] reportam

* Contribuição técnica ao 450 Seminário de Aciaria - Internacional, 25 a 28 de maio de 2014, Porto Alegre, RS, Brasil. 
que o grau de armazenamento de calor pelo revestimento refratário é predominantemente dependente da prática de pré-aquecimento da panela. $\mathrm{E}$ que após as primeiras cinco corridas, o calor armazenado na panela torna-se constante ao longo de toda a campanha daquela.
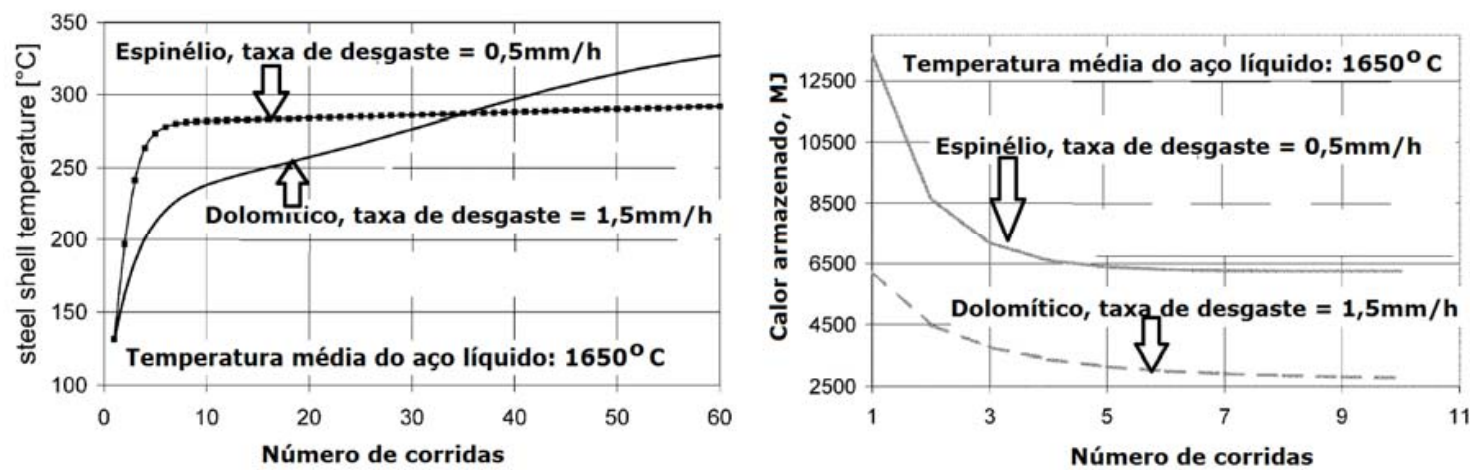

Figura 2. Temperatura da carcaça e calor armazenado na panela de refino secundário função do número de corridas, tipo e grau de desgaste do revestimento refratário, à $1650^{\circ} \mathrm{C}$ [2].

As perdas térmicas pelo topo da panela podem ser minimizadas pela presença de escória e de pó exotérmico de cobertura, além do uso de tampa. O efeito da espessura da camada de escória sobre a variação de temperatura do aço na panela é mostrado na Figura 3a. Nota-se que nos instantes iniciais (+/- 10 minutos), o emprego de camada fina ou espessa de escória de topo na panela exerce o mesmo efeito sobre a perda térmica. Contudo, após a este intervalo de tempo, a perda térmica do aço é menor para maior espessura da camada de escória. Tetrault et al. [3] e Hlinka et al. [4] mostram que o uso de tampa na panela decresce a perda térmica, Figura $3 b$, com o mesmo efeito de uma camada de escória de $15 \mathrm{~cm}$.
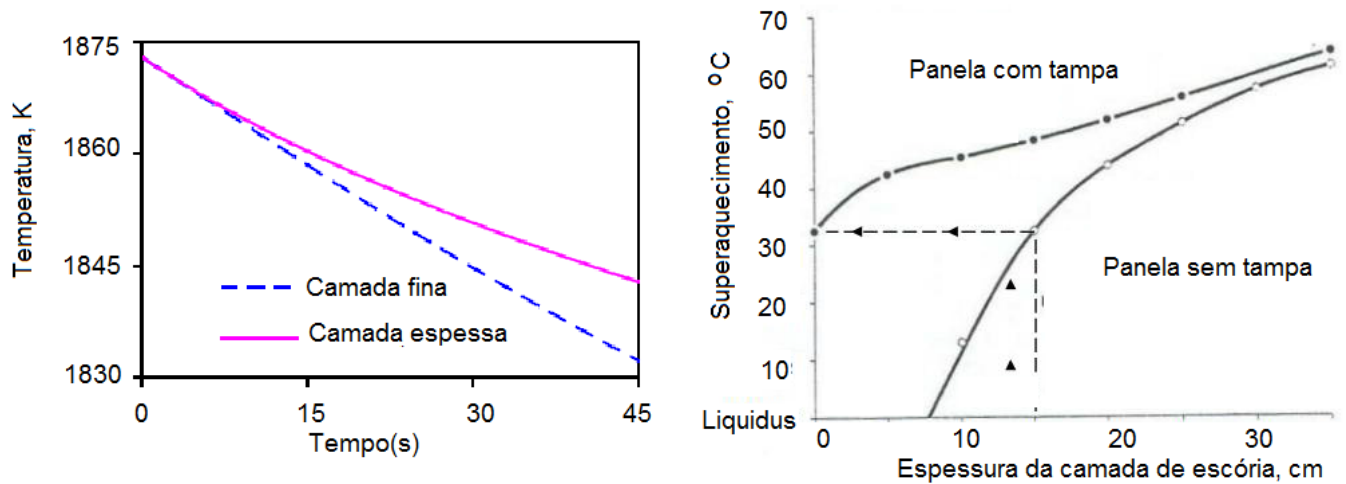

Figura 3. a) Variação da temperatura do aço líquido ao longo do tempo para duas condições de espessura de escória; b) Controle da temperatura do aço a partir de um sistema contendo tampa e outro destampado $[3,4]$.

A seguir é proposto um modelo matemático capaz de predizer as perdas térmicas em panelas de aço de formato cilíndrico, com três diferentes tipos de revestimento refratário e pela camada de dupla escória.

\section{MATERIAIS E MÉTODOS}

Para a modelagem matemática das perdas térmicas escolheu-se uma panela cilíndrica, revestida com revestimento refratário sem desgaste e cascão, além de completamente cheia de aço líquido, com capacidade aproximada para

* Contribuição técnica ao 450 Seminário de Aciaria - Internacional, 25 a 28 de maio de 2014, Porto Alegre, RS, Brasil. 
250 toneladas, Figura 4. A escória de cobertura foi constituída de duas porções distintas: líquida e sólida, com frações variáveis ao longo do tempo de retenção.

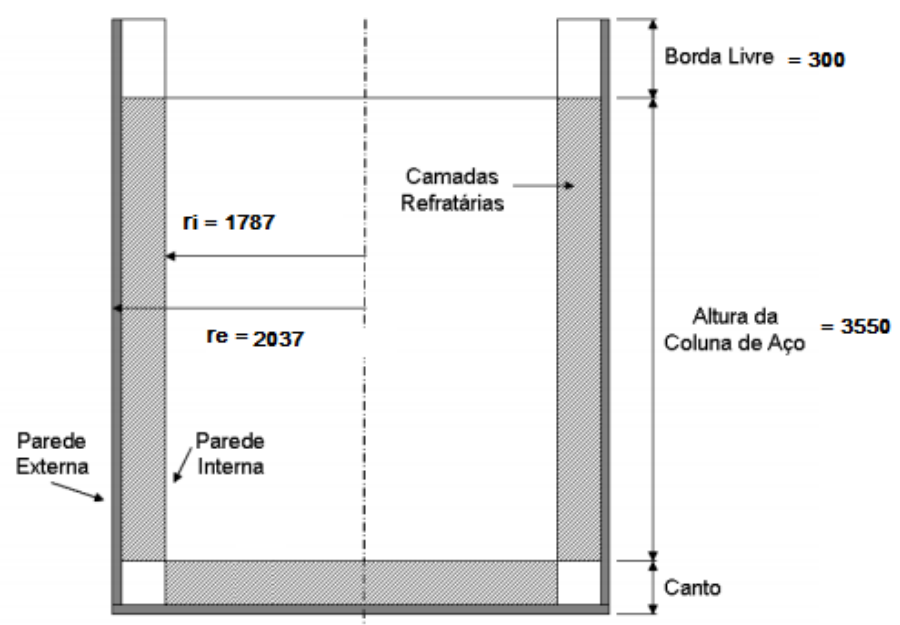

Figura 4. Representação esquemática da panela de aço.

O problema das perdas térmicas do aço contido na panela pode ser formulado como se segue:

Taxa de perda de calor pelo aço $=$ Taxa de perda de calor para o refratário + Taxa de perda de calor para a escória.

$$
\left(\rho_{m} \cdot C_{m} \cdot V \cdot \frac{d T_{m}}{d t}\right)=\left(q_{w}+q_{b}\right)+\left(q_{s}\right)
$$

onde, $\rho_{m}=$ massa específica do aço; $C_{m}=$ calor específico do aço; $V=$ volume de aço; $T_{m}=$ temperatura do aço; $t=$ tempo; $q_{w}=$ perdas térmicas para as paredes refratárias laterais, cilíndricas; $q_{b}=$ perdas térmicas para os refratários do fundo da panela; $q_{s}=$ perdas térmicas através da camada de escória, pelos mecanismos de difusão, convecção e radiação. Esta formulação matemática admite uniformidade térmica do banho metálico.

\subsection{Perdas Térmicas para o Refratário}

Estão ligadas à quantidade de energia armazenada pelo revestimento; é, portanto, uma função de geometria, tipo e grau de desgaste do revestimento, estado de encharque na panela antes do enchimento e tempo de operação. A equação primária a ser resolvida no tratamento deste problema é a equação de Fourier acoplada a condições de contorno e iniciais apropriadas:

Taxa de perda de calor para revestimento = Área de contato $\times$ Condutividade térmica do refratário x Gradiente de temperatura no refratário, na interface com o metal

$$
q_{r}=\left(A_{r}\right) \cdot\left(K_{r}\right) \cdot\left(-\frac{d T}{d r}\right)
$$

onde $A_{r}=$ área de contato refratário - aço; $K_{r}=$ condutibilidade térmica do refratário; $\frac{d T}{d r}=$ gradiente térmico na interface, no lado do refratário; $r=$ distância coordenada.

Este problema de condução de calor é mais facilmente resolvido considerando-se:

1- A espessura do refratário é grande o suficiente para que o mesmo seja considerado um sólido semi-infinito;

2- O refratário está inicialmente pré-aquecido uniformemente.

* Contribuição técnica ao 450 Seminário de Aciaria - Internacional, 25 a 28 de maio de 2014, Porto Alegre, RS, Brasil. 
Valores típicos de propriedades termofísicas de aço líquido e alguns refratários são apresentados na Tabela 1; a validade da hipótese de sólido semi-infinito pode ser testada a partir destes valores.

Tabela 1.Propriedades do aço liquido e de materiais refratários [5]

\begin{tabular}{|l|l|l|l|}
\hline Material & Propriedade & Valor & Unidade \\
\hline \multirow{2}{*}{ Aço liquido } & Densidade & 7080 & $\mathrm{Kg} / \mathrm{m}^{3}$ \\
\cline { 2 - 4 } & Calor específico & 754 & $\mathrm{~J} / \mathrm{kg}^{\circ} \mathrm{C}$ \\
\hline \multirow{2}{*}{ Refratário Dolomítico } & Densidade & 2100 & $\mathrm{Kg} / \mathrm{m}^{3}$ \\
\cline { 2 - 4 } & Condutividade térmica & 1,05 & $\mathrm{~W} / \mathrm{m}^{\circ} \mathrm{C}$ \\
\cline { 2 - 4 } & Calor específico & 1005 & $\mathrm{~J} / \mathrm{kg}^{\circ} \mathrm{C}$ \\
\hline \multirow{2}{*}{$\begin{array}{l}\text { Refratário Aluminoso } \\
\left(\mathbf{5 0 \% ~} \mathbf{A l}_{\mathbf{2}} \mathbf{O}_{\mathbf{3}}\right)\end{array}$} & Densidade & 2400 & $\mathrm{Kg} / \mathrm{m}^{3}$ \\
\hline \multirow{2}{*}{$\begin{array}{l}\text { Refratário Alta Alumina } \\
\left(>\mathbf{8 0} \% \mathbf{A l}_{\mathbf{2}} \mathbf{O}_{\mathbf{3}}\right)\end{array}$} & Condutividade térmica & 1,26 & $\mathrm{~W} / \mathrm{m}^{\circ} \mathrm{C}$ \\
\hline & Calor específico & 1005 & $\mathrm{~J} / \mathrm{kg}^{\circ} \mathrm{C}$ \\
\hline
\end{tabular}

Para um sólido semi-infinito a profundidade da penetração de calor pode ser calculada a partir da equação:

$$
\delta=4 \sqrt{t . \alpha_{r}}=4 \sqrt{t .\left(k_{r} / \rho_{r} \cdot C_{r}\right)}
$$

Onde $t=$ tempo; $\alpha_{r}=$ difusividade térmica do refratário; $\rho_{r}=$ massa especifica do refratário; $C_{r}=$ calor específico do refratário; $K_{r}=$ condutibilidade térmica do refratário.

Considerando-se um tempo de contato entre o banho de metal e o revestimento refratário de cerca de 2 horas, a profundidade de penetração irá depender da difusividade térmica. Cálculos de profundidade de penetração, utilizando-se os valores referentes à Tabela 1, permitem determinar os valores apresentados na Tabela 2.

Tabela 2. Profundidade de penetração do calor, após $2 \mathrm{~h}$, de acordo com o revestimento refratário

\begin{tabular}{|l|l|l|}
\hline Tipo de Revestimento & Difusividade Térmica $\left(\mathrm{m}^{2} / \mathrm{s}\right)$ & Profundidade $(\mathrm{m})$ \\
\hline Dolomítico & $4,975 \times 10^{-7}$ & 0,239 \\
\hline Aluminoso & $5,224 \times 10^{-7}$ & 0,245 \\
\hline Alta Alumina & $8,267 \times 10^{-7}$ & 0,309 \\
\hline
\end{tabular}

Estas distâncias estão no limiar das espessuras de um revestimento típico de panela; desta forma para tempos de retenção suficientemente curtos a hipótese de revestimento semi-infinito seria aplicável. Isto implica em que apenas uma pequena porção do calor perdido a partir do metal para o refratário penetra completamente no revestimento; que uma grande fração deste calor é simplesmente usada para aquecer o tijolo do refratário que está relativamente perto da face quente.

A suposição de temperatura de pré-aquecimento uniforme, embora não aplicável (pois existe um gradiente térmico importante no refratário, desde a interface com o metal até a carcaça), também permite uma fácil comparação dos efeitos de vários parâmetros que afetam a queda de temperatura do aço na panela.

Considerando-se todas estas condições, a taxa de perda de calor do metal para as paredes refratárias da panela é dada por:

* Contribuição técnica ao 450 Seminário de Aciaria - Internacional, 25 a 28 de maio de 2014, Porto Alegre, RS, Brasil. 


$$
q_{w}=-A_{w} \cdot K_{r} \cdot\left(T_{m}-T_{r}\right) \cdot\left(\frac{1}{2 R}+\frac{1}{\sqrt{\pi \alpha_{r} t}}\right)
$$

Enquanto que a quantidade de calor cedida aos refratários (armazenada) da parede após t (segundos) de operação é dada por:

$Q_{w}=-A_{w} \cdot K_{r} \cdot\left(T_{m}-T_{r}\right) \cdot\left(\frac{t}{2 R}+\frac{2 \sqrt{t}}{\sqrt{\pi \alpha_{r}}}\right)$

Similarmente, a taxa de perda de calor do metal para a parede refratária do fundo da panela e a quantidade total de calor armazenado nesta região são dados por:

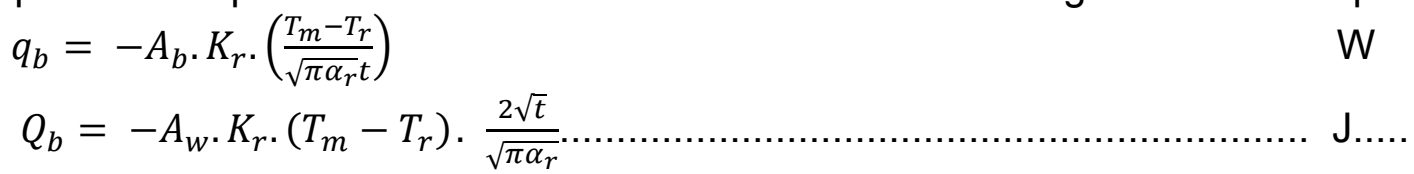

Nestas expressões $T_{m}=$ temperatura do aço; $T_{r}=$ temperatura inicial do refratário; $t=$ tempo; $\alpha_{r}=$ difusividade térmica do refratário; $K_{r}=$ condutibilidade térmica do refratário; $A_{w}=$ área de contato refratário das paredes - aço; $A_{b}=$ área de contato refratário do fundo - aço; $R=$ raio interno da panela.

\subsection{Perdas de Calor do Aço para a Escória}

Estas podem ser inferidas a partir do fluxo térmico através da camada de escória de cobertura. No topo da camada de escória, em função das perdas por radiação e convecção ao ambiente, pode haver solidificação parcial, de modo que se desenvolve uma interface móvel escória líquida/escória sólida através da qual flui o calor. Uma possível formulação, que não leva em consideração estas particularidades, sugere calcular a perda de calor através da camada de escória como $[5,6]$ :

$$
\left(q_{s}\right)=0,083 \cdot A_{s} \cdot K_{s} \cdot\left(T_{m}-T_{s}\right)^{\frac{4}{3}} \cdot\left(\frac{g \cdot \beta_{s}}{v_{s} \alpha_{s}}\right)^{\frac{1}{3}}
$$

onde $A_{s}=$ área de contato escória-banho de aço, $\mathrm{m}^{2} ; K_{s}=$ condutividade térmica da escória, $\mathrm{W} / \mathrm{m}^{\circ} \mathrm{C} ; T_{m}=$ temperatura do banho de aço, ${ }^{\circ} \mathrm{C} ; T_{s}=$ temperatura da escória, ${ }^{\circ} \mathrm{C} ; g$ = aceleração da gravidade, $\mathrm{m}^{2} / \mathrm{s} ; \beta_{s}=$ coeficiente de expansão térmica da escória, $\mathrm{K}^{-1} ; v_{s}=$ viscosidade cinemática da escória, $\mathrm{m}^{2} / \mathrm{s} ; \alpha_{s}=$ difusividade térmica da escória.

A equação 6 exprime que a taxa de perda de calor do metal para a escória é independente da espessura da camada de escória, sendo resultante da convecção natural que se instala na panela em função dos gradientes térmicos. Propriedades típicas de escórias de aciaria, que devem ser consideradas para estes cálculos, são apresentadas na Tabela 3.

Tabela 3. Propriedades termofísicas da escória [4]

\begin{tabular}{|l|l|l|l|}
\hline Material & Propriedade & Valor & \multicolumn{1}{|c|}{ Unidade } \\
\hline \multirow{5}{*}{ Escória } & Densidade & 3000 & $\mathrm{Kg} / \mathrm{m}^{3}$ \\
\cline { 2 - 4 } & Calor específico & 787 & $\mathrm{~J} / \mathrm{kg}^{\circ} \mathrm{C}$ \\
\cline { 2 - 4 } & Condutividade Térmica & 1,42 & $\mathrm{~W} / \mathrm{m}^{\circ} \mathrm{C}$ \\
\cline { 2 - 4 } & Viscosidade & 0,005 & $\mathrm{~Pa} . \mathrm{S}$ \\
\cline { 2 - 4 } & $\begin{array}{l}\text { Coeficiente de Expansão } \\
\text { Térmica }\end{array}$ & 0,0002 & ${ }^{\circ} \mathrm{K}^{-1}$ \\
\hline
\end{tabular}

Contudo, é fato que camadas espessas de escória proporcionam proteção térmica adicional ao banho. Além do mais, a possível solidificação parcial da escória impõe

* Contribuição técnica ao 450 Seminário de Aciaria - Internacional, 25 a 28 de maio de 2014, Porto Alegre, RS, Brasil. 
um mecanismo de trocas térmicas, envolvendo difusão na camada de escória e convecção - radiação na interface desta com atmosfera, como se descreve a seguir. Foi utilizado um modelo que pressupõe a existência de camada de escória liquida em contato com o banho de aço e uma camada de escória sólida que se encontra em contato com o ambiente. Conforme calor é perdido a partir da escória para a atmosfera a superfície da escória começa a solidificar. Considera-se que calor é transportado através da escória liquida que está em contato com o metal por difusão. Este calor é então conduzido através da escória sólida também por difusão; na superfície livre calor é perdido para o ambiente por radiação e convecção. A Figura 5 esquematiza uma camada dupla (liquido + sólido) de escória situada no topo de um banho de metal. Admite-se que a temperatura do metal seja conhecida e uniforme $\left(T_{m}\right)$, bem como a temperatura ambiente $\left(T_{a}\right)$.

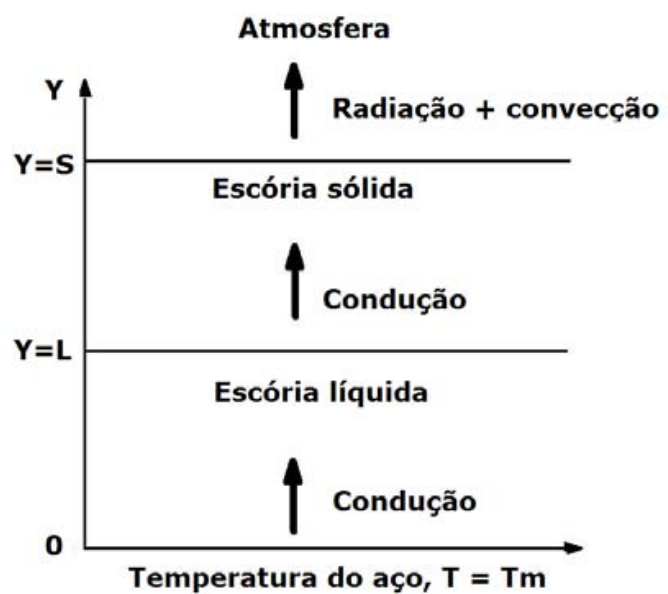

Figura 5. Desenho esquemático do processo de transferência de calor através da escória.

As equações que descrevem o fluxo são aquelas referentes à difusão unidirecional e transiente de calor em meio uniforme, associadas a condições iniciais e de contorno específicas de cada camada.

Para a camada liquida, situada tal que $0 \leq \mathrm{y} \leq \mathrm{L}$, se aplica a equação

$\left(\frac{K}{\rho C_{p}}\right)_{\text {liquido }} \cdot \frac{\partial^{2} T}{\partial y^{2}}=\frac{\partial T}{\partial t}$

onde $\frac{\mathrm{K}}{\rho \mathrm{C}_{\mathrm{p}}}=$ difusividade térmica da escória líquida; $T=$ temperatura da escória líquida; $t=$ tempo; $y=$ distância coordenada.

Condições de contorno refletem que a temperatura de aço e escória são iguais no ponto de contato, isto é, em y $=0$ (interface com o metal):

$\mathrm{T}=\mathrm{T}_{\mathrm{m}}$

Também que a interface escória líquida - escória sólida é móvel. O avanço da interface pode ser encontrado por um balanço de energia na interface, isto é, em $\mathrm{y}=\mathrm{L}$ (interface sólido/liquido):

$-\left.K_{L} \frac{d T_{L}}{d y}\right|_{y=L^{-}}+\left.K_{S} \frac{d T_{S}}{d y}\right|_{y=L^{+}}=\rho_{S} \cdot \frac{d M_{S}}{d t} \cdot \Delta H$

onde $\mathrm{dM}_{\mathrm{s}}$ representa o avanço da interface, após solidificação e $\Delta \mathrm{H}$ a variação de entalpia de solidificação da escória. A posição da interface pode ser encontrada em $\left.T\right|_{\left.\right|_{y=L}}=T_{\text {Solidus }}$ onde $T_{\text {Solidus }}$ é a temperatura solidus da escória; os índices s e L representam camada sólida e líquida, respectivamente. Esta expressão indica que a

* Contribuição técnica ao 45 Seminário de Aciaria - Internacional, 25 a 28 de maio de 2014, Porto Alegre, RS, Brasil. 
diferença entre os fluxos térmicos que atravessam a interface no lado da camada líquida e que atravessa a interface no lado da camada sólida leva à solidificação.

Por outro lado se escreve para a camada sólida, situada tal que $\mathrm{L} \leq \mathrm{y} \leq \mathrm{S}$

$$
\left(\frac{K}{\rho C_{p}}\right)_{\text {sólido }} \cdot \frac{\partial^{2} T}{\partial y^{2}}=\frac{\partial T}{\partial t}
$$

sendo $\frac{\mathrm{K}}{\rho \mathrm{C}_{\mathrm{p}}}=$ difusividade térmica da escória sólida; $T=$ temperatura da escória líquida; $t=$ tempo; $y=$ distância coordenada.

A integração desta expressão fornece o perfil térmico na camada de sólido, sujeito às condições de contorno anteriores e, ainda, sob a restrição que em $Y=S$ (interface com atmosfera), existem perdas de calor por convecção e radiação:

$$
-K \frac{d T}{d y}=h\left(T-T_{a}\right)+\sigma \epsilon\left(T^{4}-T_{a}{ }^{4}\right)
$$

Onde $K=$ condutiblidade térmica da escória sólida; $T=$ temperatura da escória sólida, na interface com a atmosfera; $y=$ distância coordenada; $h=$ coeficiente de convecção na interface escória - ambiente; $T_{a}=$ temperatura ambiente; $\sigma=$ constante de Stefan - Boltzmann; $\varepsilon=$ emissividade da escória.

Uma possível solução para este problema utiliza integração numérica. Considera-se por exemplo um espaço de integração dividido em $\mathrm{N}$ intervalos, Figura 6 , e passo de integração no tempo igual a $\Delta \mathrm{t}$ :

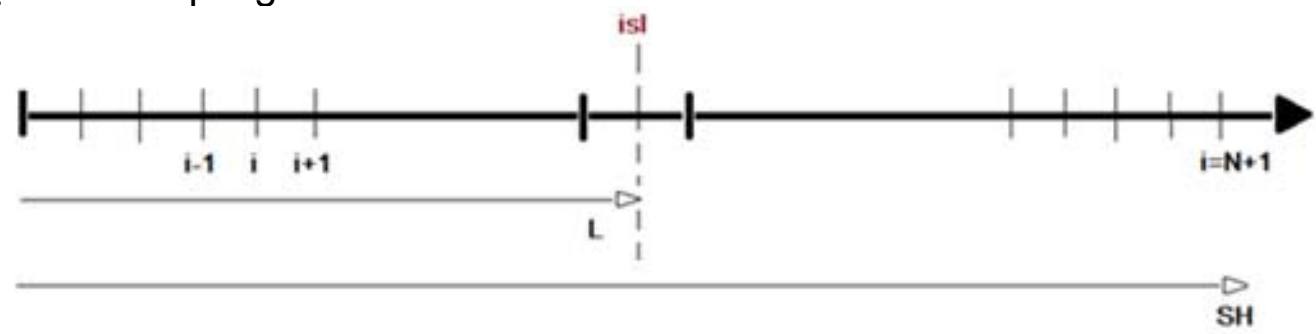

Figura 6. Discretização do espaço de integração.

Então o espaço de integração pode ser dividido em etapas de componente $\frac{\mathrm{S}}{\mathrm{N}}=\Delta \mathrm{x}$ e a equação diferencial de fluxo pode ser aproximada(em termos de diferenças finitas) a:

$$
\begin{aligned}
& -K \frac{T_{(i)}-T_{(i-1)}}{\Delta x}+K \frac{T_{(i+1)}-T_{(i)}}{\Delta x}=\Delta x \rho C_{p} \frac{d T_{(i)}}{\Delta t} \\
& \frac{K}{\Delta x^{2}}\left(T_{(i+1)}+T_{(i-1)}-2 T_{(i)}\right)=\rho C_{p} \frac{d T_{(i)}}{\Delta t} \\
& \frac{K}{\Delta x^{2}}\left(T_{(i+1)}+T_{(i-1)}-2 T_{(i)}\right)=\rho C_{p}\left(T_{(i)} \text { new }-T_{(i)}{ }^{\text {old }}\right) / \Delta t \\
& T_{(i)}{ }^{\text {new }}=T_{(i)}{ }^{\text {old }}+\frac{K}{\rho C_{p}} \cdot \frac{\Delta t}{\Delta x^{2}}\left\{T_{(i+1)}+T_{(i-1)}-2 T_{(i)}\right\}
\end{aligned}
$$

Para este esquema explícito de integração numérica utiliza-se como critério de estabilidade numérica: $\lambda=\frac{\Delta t}{\Delta x^{2}} \leq \frac{1}{2}$, para adequar os valores dos passos de integração no tempo e espaço.

As condições iniciais se resumem a:

$$
\begin{gathered}
2 \leq i \leq N \\
T_{(i=1)}=T_{M}
\end{gathered}
$$

Enquanto que, a todo instante, na interface escória - ambiente

$$
-K \frac{T_{(N)-} T_{(N-1)}}{\Delta x}=h\left(T_{(N)}-T_{a}\right)+\sigma \epsilon\left(T_{(N)}{ }^{4}-T_{a}{ }^{4}\right)
$$

\footnotetext{
* Contribuição técnica ao $45^{\circ}$ Seminário de Aciaria - Internacional, 25 a 28 de maio de 2014, Porto Alegre, RS, Brasil.
} 
Desta forma as etapas de integração seriam:

Condição inicial $t=0, T_{(i)}=T_{M}$, para todos os pontos i=1 a $\mathrm{N}+1$

A integração é feita no sentido interface com atmosfera $\rightarrow$ interface solido/liquido, de modo a propagar ao interior da camada da escória a perturbação sentida na superfície. A perturbação é quantificada pelo valor de temperatura no nó $(\mathrm{N}+1)$, determinada pelo balanço térmico

$$
\begin{aligned}
& -K \frac{T_{(N+1)-} T_{(N)}}{\Delta x}=h\left(T_{(N+1)}-T_{a}\right)+\sigma \epsilon\left(T_{(N+1)}{ }^{4}-T_{a}{ }^{4}\right) \\
& T_{(N+1)}=T_{(N)}-\frac{h \Delta x}{K}\left\{T_{(N+1)}-T_{a}\right\}-\frac{\Delta x \cdot \sigma \cdot \epsilon}{K}\left\{T_{(N+1)}{ }^{4}-T_{a}{ }^{4}\right\}
\end{aligned}
$$

Ao se propagar o efeito da perturbação ao interior, através da equação

$$
T_{(i)}^{\text {new }}=T_{(i)}^{\text {old }}+\alpha \frac{\Delta t}{\Delta x^{2}}\left\{T_{(i+1)}+T_{(i-1)}-2 T_{(i)}\right\}
$$

deve-se verificar a posição da interface sólido - líquido, de forma a adotar

$$
\begin{aligned}
& T_{(i)}{ }^{\text {new }}>T_{\text {solidus }} \alpha=\alpha_{L} \text { (liquido) } \\
& T_{(i)}{ }^{\text {new }} \leq T_{\text {solidus }} \alpha=\alpha_{S}(\text { solido })
\end{aligned}
$$

A posição inicial de interface sólido/liquido pode ser assumida como $i s l=N$; como o fluxo térmico nesta interface provoca solidificação adicional. Então

$$
-K_{L} \frac{T_{(i s l)}-T_{(i s l-1)}}{\Delta x}+K_{S} \frac{T_{(i s l+1)}-T_{(i s l)}}{\Delta x}=\rho_{s} \cdot \Delta H \cdot \frac{\Delta N}{\Delta t}
$$

ou

$$
\Delta N=\frac{\Delta t}{\rho_{s . \Delta H . \Delta x}}\left\{-K_{L}\left(T_{(i s l)}-T_{(i s l-1)}\right)+K_{S}\left(T_{(i s l+1)}-T_{(i s l)}\right)\right\}
$$

$\mathrm{E}$, ainda, o avanço da interface

$$
\Delta_{i s l}=\frac{\Delta N}{\Delta x}
$$

Este procedimento foi implementado em programa especialmente desenvolvido, e os resultados são apresentados a seguir.

\section{RESULTADOS E DISCUSSÃO}

As Figuras 7, 8 e 9 mostram os efeitos da espessura da camada de escória de cobertura, da temperatura do aço e do coeficiente de convecção, sobre o fluxo de calor através da camada de escória no topo da panela. Para estas simulações admitiu-se condutibilidade térmica da ordem de $1,21 \mathrm{~W} / \mathrm{m}^{\circ} \mathrm{C}$, densidade de $3000 \mathrm{~kg} / \mathrm{m}^{3}$, calor específico igual a $835 \mathrm{~J} / \mathrm{K} . \mathrm{kg}$, além de temperatura Solidus igual a $1673 \mathrm{~K}$, entalpia de fusão $453000 \mathrm{~J} / \mathrm{kg}$ e emissividade igual a 0,5 . Valores de propriedades termofísicas de escórias são extremamente dependentes da composição e temperatura, de modo que estes valores devem ser considerados como valores típicos de escórias de panela. Nota-se que para os valores considerados não parece haver influência significativa sobre as perdas térmicas. No caso das Figuras 8 e 9, a aparente igualdade da perda térmica da panela pode ser atribuída à pouca diferença entre as magnitudes das temperaturas e dos coeficientes de convecção, respectivamente.

\footnotetext{
* Contribuição técnica ao 450 Seminário de Aciaria - Internacional, 25 a 28 de maio de 2014, Porto Alegre, RS, Brasil.
} 

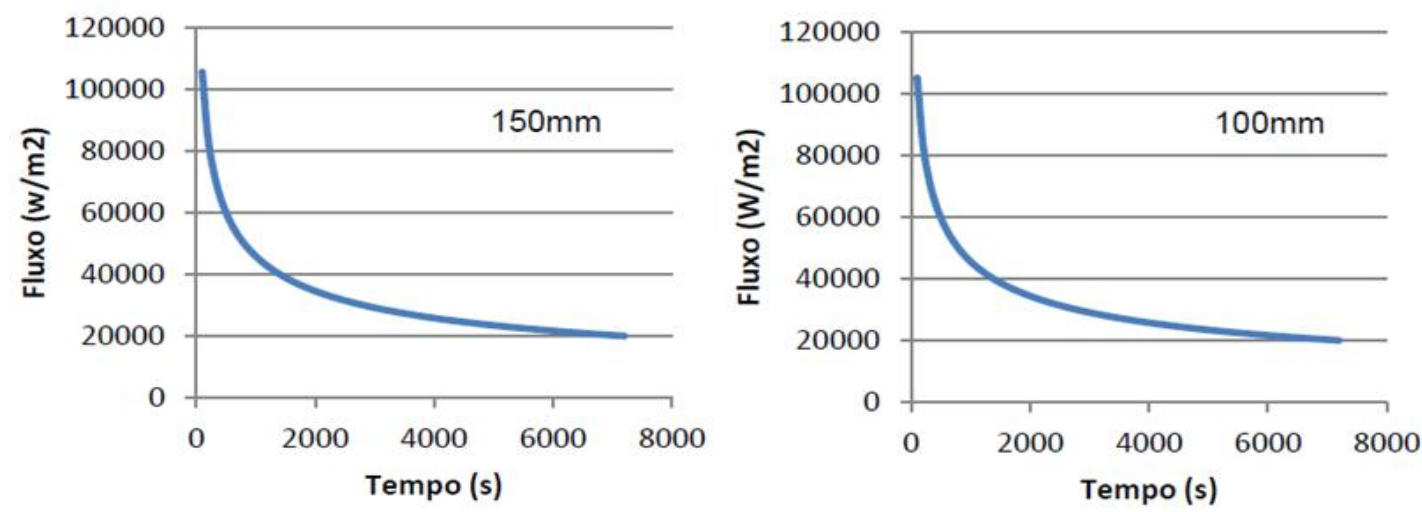

Figura 7. Fluxo de calor para diferentes valores de alturas da camada de escória a) 150mm e b) $100 \mathrm{~mm}$.
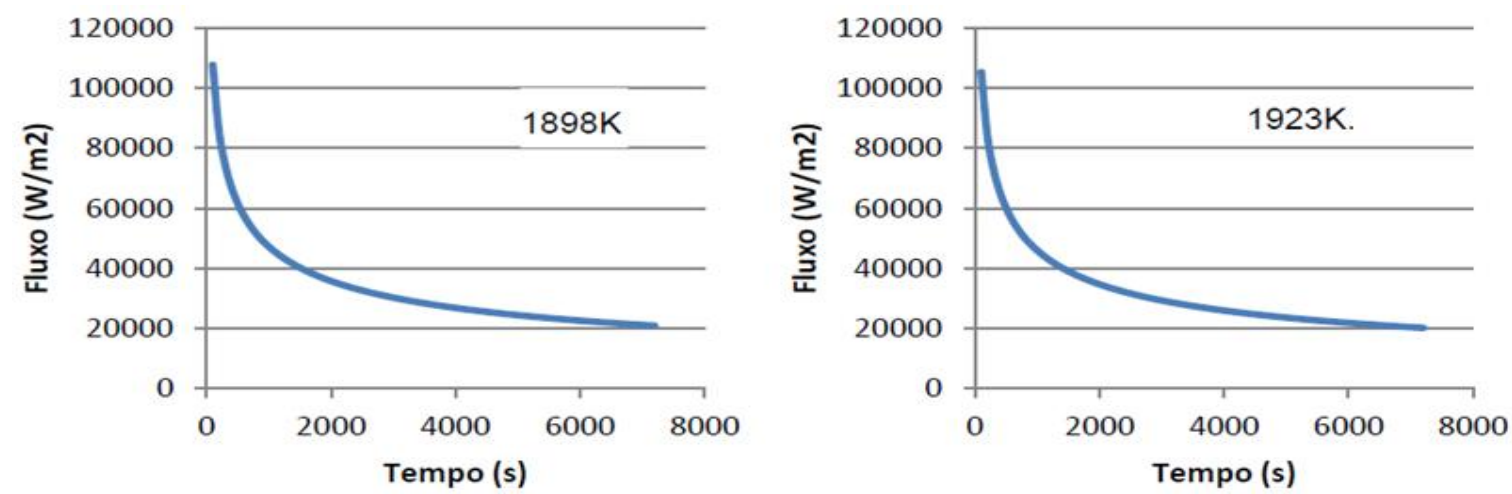

Figura 8. Fluxo de calor para diferentes valores de temperatura do aço liquido a) $1898 \mathrm{~K}$ e b) $1923 \mathrm{~K}$.
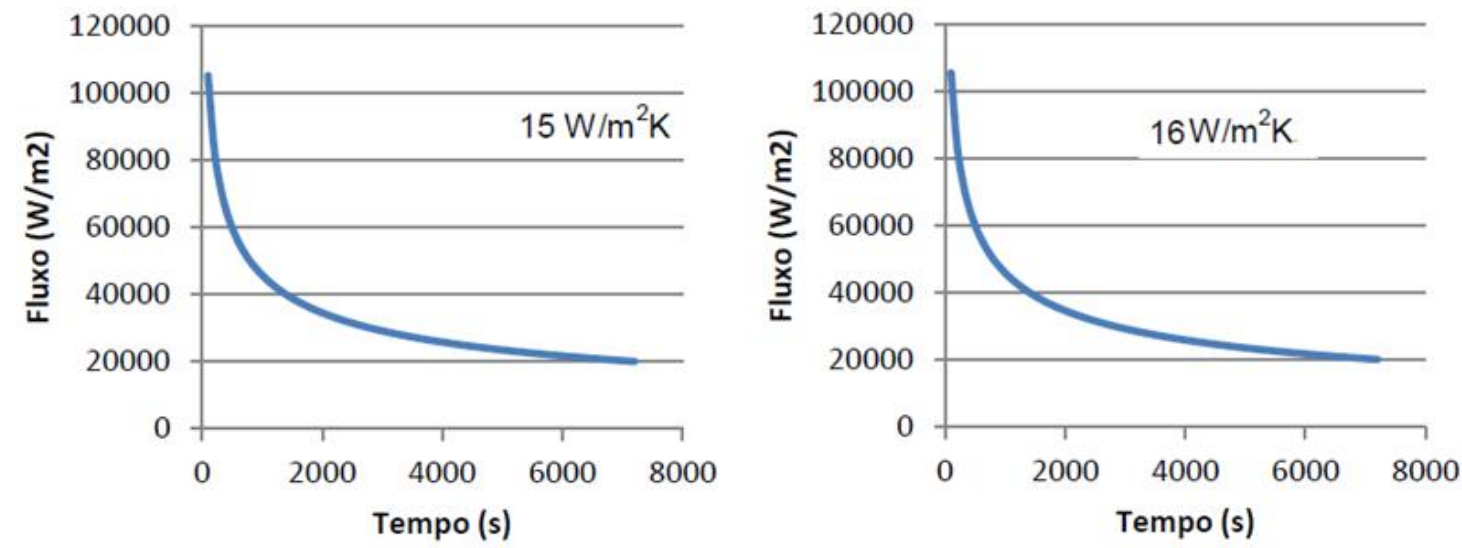

Figura 9. Fluxo de calor para diferentes valores de coeficiente de convecção a) $15 \mathrm{~W} / \mathrm{m}^{2} \mathrm{~K}$ e b) 16 $\mathrm{W} / \mathrm{m}^{2} \mathrm{~K}$.

Regressão múltipla, referente a dados obtidos de simulações mais abrangentes, sugere estimar o fluxo calor através da camada dupla de escória como:

$\mathrm{q}_{\text {esc }}=\mathrm{A}_{\text {esd }}(1550613440 \mathrm{1}+18 \mathrm{Z}) \mathrm{t}^{-0,402}$ Wattspara $\mathrm{t}>10 \mathrm{C}$

onde $\mathrm{T}$ é a temperatura do aço líquido, em $\mathrm{K} ; \mathrm{h}$ é a altura inicial da camada de escória, em mm; $A_{\text {esc }}$ é a área da interface escória - atmosfera, em $\mathrm{m}^{2}$; t é o tempo, ems.

As perdas térmicas pelo revestimento refratário da panela dependem do tipo de material refratário. Tabela 4 compara as perdas térmicas em panelas de refino do

* Contribuição técnica ao $45^{\circ}$ Seminário de Aciaria - Internacional, 25 a 28 de maio de 2014, Porto Alegre, RS, Brasil. 
aço com diferentes tipos de revestimento refratário: dolomítico, aluminoso e alta alumina. Destes três tipos de revestimento da panela, o revestimento dolomítico é o que mostrou menores perdas de calor pela lateral e fundo da panela. Para estes três tipos de revestimento refratário, as perdas de calor pela parede lateral da panela foram de quatro vezes as perdas de calor pelo fundo da mesma, mesma razão de áreas de fluxo.

Tabela 4. Perdas de calor pelo revestimento refratário da panela, para $t=2 h$, equações (4) e (5)

\begin{tabular}{|c|c|c|c|}
\hline Tipo de refratário & Parede lateral & Fundo da panela & Unidade \\
\hline Dolomítico & -635139 & -157500 & W \\
Aluminoso & -744445 & -184445 & W \\
Alta alumina & -1182667 & -292083 & W \\
\hline
\end{tabular}

As perdas térmicas diminuem ao longo do tempo. Porque, os refratários se aquecem reduzindo a força motriz de condução, por que as perdas por radiação na interface escória sólida - ambiente decrescem. O modelo de transferência de calor na camada de escória sugere que a temperatura da interface decresce acentuadamente ao longo do processo, o que se traduz em perdas menores por radiação. Desta forma, a taxa de diminuição de temperatura, inicialmente alta, diminui acentuadamente. A participação relativa de paredes, fundo da panela e camada de escória é mostrada na Figura 10, para duas temperaturas de encharque de panela. A título de referência a radiação a partir de uma superfície desprotegida de aço líquido pode gerar fluxo térmico da ordem de $700 \mathrm{~kW} / \mathrm{m}^{2}$, o que implica, para esta panela, perdas da ordem de $7 \times 10^{6} \mathrm{~W}$ ou de cerca de $9,5 \mathrm{~K} / \mathrm{min}$. Os dados ressaltam ainda o efeito do encharque térmico do refratário.
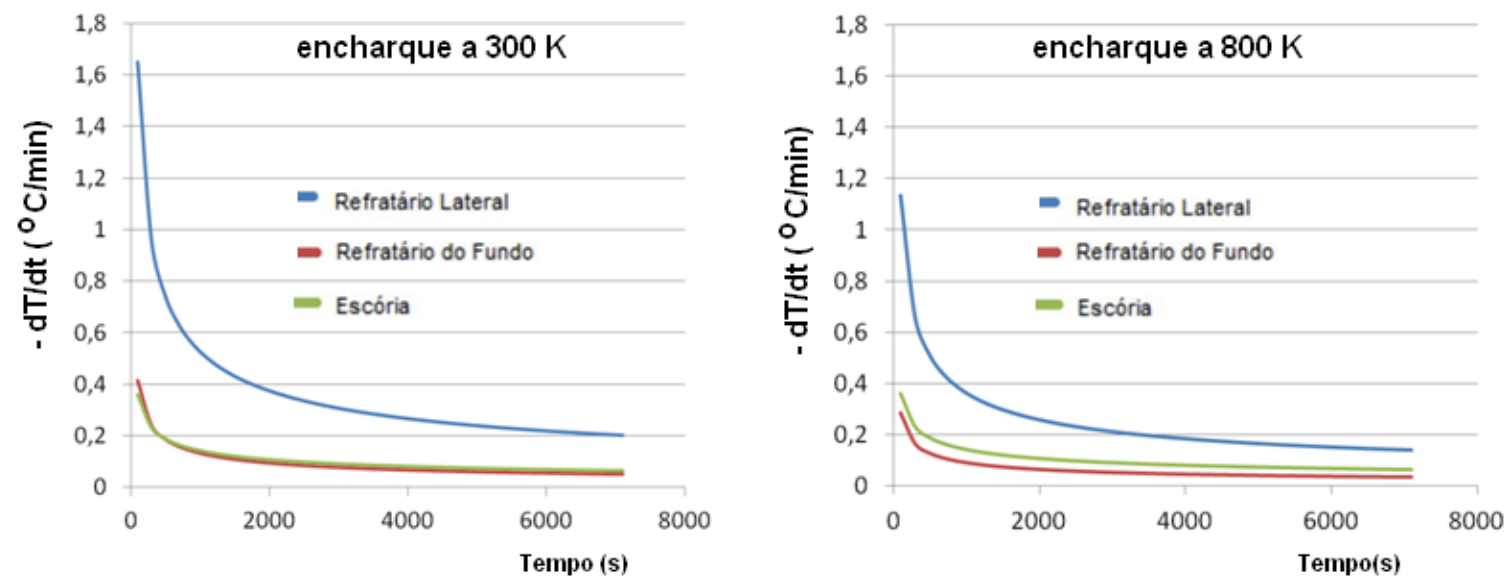

Figura 10. Perdas térmicas através da escória de cobertura, refratários da parede e fundo da panela ao longo tempo, espessura de escória de 150mm.

Os resultados obtidos indicam que panelas revestidas com refratários dolomíticos apresentam menores perdas de calor. Além disso, a camada de escória exerce influência comparável à dos refratários, sobre a perda de calor da panela. Contudo, a parede lateral da panela é a principal responsável pelas perdas térmicas. Estas assertivas são consoantes com os estudos de Gastón et al. [1], Volkova \& Janke [2], Hinka et al.[4], Pan Y \& Björkman [7], Glaser [8] e Urquhart \& Guthrie [9]. Estes autores apontam ainda a importância de considerar as influências da prática de préaquecimento de panelas novas; tempo de espera e tempo de panela vazia; nível de aço, além do perfil de desgaste do revestimento refratário sobre as perdas térmicas.

* Contribuição técnica ao 450 Seminário de Aciaria - Internacional, 25 a 28 de maio de 2014, Porto Alegre, RS, Brasil. 


\section{CONCLUSÕES}

As perdas térmicas específicas (por unidade de área), via escória de cobertura, para as espessuras consideradas, foram comparáveis às dos revestimentos refratários da parede lateral e do fundo. A parede lateral da panela mostrou-se a principal responsável pela perda térmica da panela. As perdas térmicas pela camada de dupla camada de escória dependem da temperatura do aço, espessura da escória e do tempo e podem ser quantificadas pela correlação:

$\mathrm{q}_{\text {esc }}=\mathrm{A}_{\text {esc }}(1550613-440 \mathrm{~T}+182 \mathrm{~h}) \mathrm{t}^{-0,402}$ para $\mathrm{t}>100 \mathrm{~s}$

Para os revestimentos refratários considerados, as perdas de calor pela parede lateral da panela foram quatro vezes maiores do que as perdas de calor pelo fundo da panela.

\section{Agradecimentos}

À FAPEMIG, CAPES e CNPq pelo apoio financeiro.

\section{REFERÊNCIAS}

1 Gastón A, Sanchez SG, Begnis JSS. Thermal analysis of a continuous casting tundish by an integrated fem code. Latin American Applied Research; 2008. p. 259 -266.

2 Volkova O, Janke D. Modelling of temperature distribution in refractory ladle lining for steelmaking. ISIJ International. 2003;43(8):1185-90.

3 Tetrault C, Roldan D, Zhou CQ. CFD Analysis of thermal behavior of refarctory in steel ladle cycling. In: AISTech Proceedings. 2004;1:1205-14.

4 Hlinka J W, Cramb AW, Bright DH. A Model for predicting the thermal history of a ladle of steel. In: Steelmaking Conference - vol. 68; 1985, Detroit, USA. 1985. p.14-17.

5 Omotani MA, Heaslip LJ, Mclean A. Ladle temperature control during continuous casting. Iron Steelmaker. 1983;Oct10:29-35.

6 Lopes HLP. Modelo para previsão da condição térmica de panelas de aciaria[dissertação de mestrado em Engenharia Metalúrgica e de Minas]. Belo Horizonte: UFMG; 2007.

7 Pan Y, Björkman B. Physical and mathematical modelling of thermal stratification phenomena in steel ladles. ISIJ International. 2002;42(6):614-623.

8 Glaser B. A Study on the thermal state of steelmaking ladles[ tese de doutorado]. Stockholm: Department of Materials Science and Engineering, Royal Institute of Technology School of Industrial Engineering and Management; 2012.

9 Urquhart RC, Guthrie RIL, Howat, DD. Heat losses from ladles during the teeming. Journal of the South African Institute of Mining and Metallurgy. 1973;74(4):132-139.

* Contribuição técnica ao 45 Seminário de Aciaria - Internacional, 25 a 28 de maio de 2014, Porto Alegre, RS, Brasil. 